\title{
Estratégias de Ensino em Solos sob o Olhar das Tendências Pedagógicas
}

\author{
Strategies of Teaching on Soils under the View of Pedagogical Trends
}

\section{Estrategias de Enseñanza en Suelos desde el Punto de Vista de las Tendencias Pedagógicas}

\author{
Cibele Stefanno Saldanha ${ }^{1}$ \\ https://orcid.org/0000-0003-3331-8253 \\ Tuane Telles Rodrigues ${ }^{2}$ \\ https://orcid.org/0000- 0003-0747-6004 \\ Marcia Elena de Mello Cardias ${ }^{3}$ \\ https://orcid.org/0000-0001-0002-7422-3018
}

\begin{abstract}
RESUMO: O solo é um recurso essencial para o funcionamento dos ecossistemas, mesmo que não seja devidamente pontuado no ensino escolar. O presente estudo buscou desenvolver a discussão sobre o ensino de solos através das perceptivas educacionais impulsionadas pelas tendências pedagógicas liberal tradicional e liberal renovada progressivista. Assim, objetivou-se verificar qual método seria mais eficiente ao ensino em solos com alunos do $6^{\circ}$ ano de uma escola municipal de Santa Maria, no Rio Grande do Sul. Para tanto, utilizou-se como estratégia a divisão das turmas pesquisadas, em uma delas realizou-se o trabalho através da tendência pedagógica liberal progressivista (definida como turma de trabalho), e na outra sob a perspectiva liberal tradicional (definida como turma de controle). Na primeira utilizou-se a experimentoteca para demonstrar os conceitos morfológicos do solo através do manuseio e da aplicação dos conceitos de sua morfologia, dando ênfase à sua consistência, enquanto na segunda realizou-se apenas a exposição teórica dos conteúdos. Por fim, as duas tendências pedagógicas demonstraram-se satisfatórias e eficientes, contudo na turma em que se realizou a abordagem pedagógica progressivista os alunos mostraramse mais curiosos e interessados pelos conteúdos.
\end{abstract}

PALAVRAS-CHAVE: Ensino de Geografia. Tendências pedagógicas. Solos.

\footnotetext{
${ }^{1}$ Doutoranda do Programa de Pós-graduação em Geografia da Universidade Federal de Santa Maria (UFSM). Email: cibele2012stefanno@gmail.com.

${ }^{2}$ Doutoranda do Programa de Pós-graduação em Geografia da Universidade Federal de Santa Maria (UFSM). Email: tuanytel@hotmail.com.

${ }^{3}$ Doutoranda do Programa de Pós-graduação em Geografia da Universidade Federal de Santa Maria (UFSM). Email: mailto:tuanytel@hotmail.comelenamarcia83@gmail.com.mailto:tuanytel@hotmail.com
} 


\begin{abstract}
Soil is an essential resource for the functioning of ecosystems, even if it is not properly scored in school education. In this way, the present study sought to develop the discussion on soil teaching through educational perspectives driven by pedagogical trends: traditional liberal and progressive renewed liberal. Thus, the objective was to verify which method would be more efficient to teach in soil with students of the 6th year of a municipal school in Santa Maria, in Rio Grande do Sul. of them, the work was carried out through the progressive pedagogical tendency (defined as the work group), and the other under the traditional liberal perspective (defined as the control group). In the first, the experiment library was used to demonstrate the morphological concepts of the soil through the handling and application of the concepts of its morphology, emphasizing its consistency, while in the second, only the theoretical exposition of the contents was carried out. Finally, the two pedagogical tendencies proved to be satisfactory and efficient, however, in the class in which the progressive pedagogical approach was carried out, the students were more curious and interested in the contents.
\end{abstract}

KEYWORDS: Geography teaching. Pedagogical trends. Soils.

RESUMEN: El suelo es un recurso esencial para el funcionamiento de los ecosistemas, incluso si no se califica adecuadamente en la educación escolar. De esta forma, el presente estudio buscó desarrollar la discusión sobre la enseñanza del suelo a través de perspectivas educativas impulsadas por tendencias pedagógicas: liberal tradicional y progresista progresista renovado. Así, el objetivo fue verificar qué método sería más eficiente para enseñar en suelo con alumnos de $6^{\circ}$ año de una escuela municipal en Santa María, en Rio Grande do Sul. De ellos, el trabajo se llevó a cabo a través de la pedagógica liberal progresista. Tendencia (definida como el grupo de trabajo), y la otra bajo la perspectiva liberal tradicional (definida como el grupo de control). En el primero, se utilizó la biblioteca experimental para demostrar los conceptos morfológicos del suelo a través del manejo y aplicación de los conceptos de su morfología, enfatizando su consistencia, mientras que en el segundo, solo se realizó la exposición teórica de los contenidos. Finalmente, las dos corrientes pedagógicas demostraron ser satisfactorias y eficientes, sin embargo, en la clase en la que se llevó a cabo el enfoque pedagógico progresivo, los estudiantes mostraron más curiosidad e interés por los contenidos.

PALABRAS CLAVE: Enseñanza de Geografía.Tendencias pedagógicas. Suelos.

\title{
INTRODUÇÃO
}

O ensino de solo é pouco discutido no meio acadêmico e na educação básica. Esta afirmação pode ser facilmente confrontada ao analisarmos o que há de publicações sobre o tema em eventos e periódicos, bem como nos materiais didático-pedagógicos voltados à educação básica. Tal insuficiência traz consigo problemas significativos: o primeiro é o desconhecimento dos conteúdos sobre os solos, a tipagem, a composição, a localização, os aspectos socioeconômicos envolvidos e o manuseio inadequado, entre outros; e o segundo se refere a uma lacuna nas discussões que integram a Educação Ambiental, a exemplo da importância do manto pedológico para os sistemas ambientais.

O estudo do solo tem se apresentado como uma necessidade real, dado a importância no desempenho das atividades humanas pois, desde a antiguidade, a humanidade extrai recursos e apropria-se dos solos para produzir alimentos, fixar moradias e realizar suas 
atividades em sociedade. Os homens primitivos viam o solo apenas como algo existente sob a superfície da Terra. Era o local onde se movimentavam, retiravam materiais para confeccionar alguns objetos, pigmentos para suas pinturas. O solo era visto como algo que se confundia com o restante da crosta terrestre e pensado como fixo e imutável (LEPSCH, 2002).

Segundo Muggler et al. (2004), de maneira geral as pessoas têm uma atitude de pouca consciência e sensibilidade em relação ao solo, como se o mesmo não fizesse parte da esfera ambiental, o que contribui para a sua degradação, seja pelo seu manejo inadequado ou pela sua ocupação desordenada. Destacam que a percepção da importância e da necessidade da conservação dos solos não faz parte, ou está pouco inserida, no cotidiano da população e isso contribui para o intenso crescimento dos problemas ambientais relacionados à degradação do solo.

O objeto da pesquisa, portanto, foi a de verificar a eficácia das tendências pedagógicas (Tradicional e Renovada Progressivista) no ensino em solos com ênfase na morfologia do solo com os alunos de suas turmas do $6^{\circ}$ ano da Escola Municipal de Ensino Fundamental Euclides da Cunha, localizada em Santa Maria/ RS. Essa pesquisa se justifica pela insuficiência na compreensão da importância do solo como um sistema face ao meio ambiente, como vem sendo reproduzida ao longo de décadas na educação básica.

Neste sentido, a pesquisa levanta a hipótese de que é possível desenvolver o ensino em solos com o auxílio dos métodos propostos pelas tendências pedagógicas. As tendências pedagógicas passaram por diversas reflexões e perspectivas registrados ao longo dos últimos séculos e neste processo as teorias transcorreram uma trajetória histórica, percorrendo as teorias tradicionais, críticas e pós-críticas. Estas teorias trouxeram contribuições para o ensino ao longo dos séculos, que permanecem na atualidade.

O ensino tradicional foi pioneiro nas tendências pedagógicas. Este vem sofrendo diversas críticas no modo em que o professor conduz as aulas, pois se referem ao ensino autoritário na qual o professor é o protagonista, detentor de todo conhecimento e saber, a aula é expositiva e o método irrefutável. Os educandos não interagem com o professor e aprendem através da memorização. Os conhecimentos são canalizados em questões técnicas e tais conhecimentos não estão associados ao entendimento prévio dos educandos ancorados na vivência que eles possuem, desta forma a aprendizagem não se torna significativa.

A partir do Movimento da Escola Nova, em meados de 1930, surgiu a Tendência Pedagógica Liberal Renovada Progressivista, a qual se opôs à Tendência Liberal Tradicional trazendo outras reflexões ao ensino, revolucionando o ensino tradicional da época. Na Tendência Liberal Tradicional o professor possui espaço privilegiado. Já na Tendência Pedagógica Liberal Renovada o professor passa a ser um auxiliar na 
aprendizagem por meio do desenvolvimento livre e espontâneo do educando que antes era passivo e passa a ser ativo.

A Tendência Liberal Renovada valoriza os processos mentais e habilidades cognitivas dos educandos como sendo mais eficazes do que os conteúdos propriamente ditos. A aprendizagem dos educandos deve ser construída com base em suas experiências. Para Lagar, Santana e Dutra (2013) a Tendência Liberal Renovada dá voz ao aluno tornando-se um verdadeiro laboratório de ensino.

A Escola Progressivista é aquela que dá espaço ao fazer, ao experimentar. O professor progressivista é aquele que visa a facilitação da aprendizagem do aluno, tornando-o autônomo e livre para aprender e alimentar a sua estrutura cognitiva. Já o aluno progressivista é aquele que se sente livre para falar, agir e transformar. É aquele que assume a responsabilidade sobre a sua aprendizagem e convive em harmonia com todos ao seu redor, respeitando o espaço de cada um e contribuindo para a elevação do coletivo ao invés do individual. Tornado uma descoberta, o ambiente é apenas um meio estimulador da aprendizagem (LIBÂNEO, 1989).

\section{METODOLOGIA}

A pesquisa iniciou-se com a escolha de duas turmas do sexto ano, uma denominada turma de trabalho (turma 61) e a outra denominada turma de controle (turma 62). Na turma de trabalho foi aplicada a metodologia proposta pela Tendência Pedagógica Liberal Renovada Progressivista (experimentotecas). Já na turma de controle utilizou-se o método sugerido na tendência tradicional, e a aula foi predominantemente expositiva, utilizando o livro didático no ensino em solos.

O trabalho dividiu-se em duas etapas: etapa de gabinete e etapa de campo. A etapa de gabinete contou com o levantamento bibliográfico acerca dos conceitos que tangem a pesquisa, e são eles: tendências pedagógicas; ensino em solo; experimentoteca; morfologia do solo; e consistência do solo. Para dar início à etapa de campo foi necessária a coleta das amostras em campo. Em seguida as amostras passaram pela secagem e peneiramento. Foram transportados alguns materiais laboratoriais para sala de aula como copos becker e conta-gotas, que foram disponibilizados pelo Laboratório de Sedimentologia da Universidade Federal de Santa Maria.

A turma de controle (62) contou com a metodologia habitual que valoriza quase que em sua totalidade o uso do quadro negro e o livro didático de Geografia (Expedições Geográficas $-6^{\circ}$ ano) adotado pela escola. O método pedagógico utilizado para conduzir a 
explanação do conteúdo de solos foi expositivo, e dialogado seguindo a tendência tradicional.

A turma de trabalhofoi escolhida para desenvolver as experimentotecas devido à menor quantidade de educandos. Dessa forma, foi possível se dedicar aos questionamentos pertinentes ao tema e observar a interação dos educandos no desenvolver da experimentoteca. Os materiais escolhidos para aplicação da experimentoteca com os educandos foram criteriosamente selecionados para servirem como conceitos subsunçores, e posteriormente abordar os conceitos mais complexos que abrangem a morfologia do solo. As amostras foram trazidas secas e prontas para realizar as atividades experimentais na escola.

$\mathrm{Na}$ turma de trabalho, a aula teve caráter expositivo, prático e participativo. O quadro 1 traz as descrições da experimentoteca (aplicada apenas na turma de trabalho), materiais utilizados e os procedimentos necessários para realização das atividades.

Quadro 1 - Descrições da experimentoteca aplicadas na E.M.E.F. Euclides da Cunha

\begin{tabular}{|c|c|c|}
\hline Experimentoteca & Materiais Utilizados & Procedimentos \\
\hline $\begin{array}{l}\text { Análise das diferentes } \\
\text { consistências do solo. }\end{array}$ & $\begin{array}{l}\text { Para desenvolver a } \\
\text { experimentoteca com os } \\
\text { educandos da turma } 61 \text { foram } \\
\text { necessários os seguintes } \\
\text { materiais: três copos Becker, } \\
\text { amostras de solos com } \\
\text { diferentes composições } \\
\text { granulométrica e teor de } \\
\text { umidade (seco, úmido e } \\
\text { molhado) e um recipiente com } \\
\text { água. }\end{array}$ & $\begin{array}{l}\text { Os educandos manusearam as } \\
\text { amostras determinando o } \\
\text { estado de umidade de cada } \\
\text { uma delas, ou seja, a } \\
\text { consistência do solo seco, } \\
\text { úmido e molhado. }\end{array}$ \\
\hline
\end{tabular}

Fonte: elaborado pelas autoras.

\section{REFERENCIAL TEÓRICO}

As tendências pedagógicas foram classificadas em três categorias, nas quais interpretam a questão da educação na sociedade: a) educação como redenção; b) educação como reprodução e c) educação como transformação da sociedade. "A perspectiva redentora se traduz pelas pedagogias liberais e a perspectiva transformadora pelas pedagogias progressistas" (LUCKESI, 1993, p. 53).

Para desenvolver a abordagem das tendências pedagógicas utilizamos como critério a posição que cada tendência adota em relação às finalidades sociais da escola. Dessa forma, Libâneo (1989) propõe uma classificação para as pedagogias, organizando-as em dois grandes grupos, conforme aparece a seguir: a) Pedagogia Liberal: Tradicional; Renovada Progressivista; Renovada Não-Diretiva; Tecnicista; b) Pedagogia Progressista: Libertadora; Libertária; Crítico-Social dos Conteúdos. 
Das pesquisas relacionadas ao ensino de solos, considerou-se também as de Hartemink et al. (2014, p. 1) acerca da satisfação ao ensinar solos e por considerarem que "[...] around the world, university teaching principles are changing as students also gain knowledge and inspiration in ways other than in the class room". Field et al. (2011), por sua vez são abordados nesta pesquisa pelos princípios no ensino de solos e Brevik (2009) por discutir sobre o ensino da Ciência do Solo em Geologia, Geografia, Ciências Ambientais e Programas Agrícolas.

\section{Pedagogia Tradicional}

A tendência tradicional caracteriza-se por enfatizar o ensino humanístico. A explanação dos conteúdos, os procedimentos didáticos, e a relação professor-aluno não possui nenhuma relação com o cotidiano do educando e muito menos com as realidades sociais. O educador é o protagonista das regras impostas, do cultivo exclusivamente intelectual.

A escola tem o papel fundamental na preparação intelectual e moral dos educandos para assumir sua posição na sociedade. Neste sentido, os conteúdos de ensino são fundamentados nos conhecimentos e valores sociais que são transferidos através das gerações com veracidade. A tendência tradicional se preocupa com preparação do educando para vida, e sua atuação na sociedade. As disciplinas e os conteúdos não têm relação com as vivências dos educandos tão pouco com as realidades sociais contempladas pelo mesmo (LIBÂNEO, 1989).

\section{Pedagogia Renovada Progressivista}

Em 1902, John Dewey escreveu a obra The Child and the Curriculum, onde defendeu a renovação do ensino tradicional e o chamado ensino pela ação, neste sentido o professor é um auxiliar e o educando passa a ser ativo e não mais passivo. Dewey considerava a experiência das crianças e jovens fundamentais para que ocorra de fato a aprendizagem, o aprender fazendo através da pesquisa, ele preocupava-se com a construção da democracia liberal. Nesta mesma linha de pensamento destacaram-se grandes nomes como Jean Piaget, Maria Montessori, Lauro de Oliveira Lima, Jean-Ovide Decroly e Anísio Teixeira, entre outros.

Segundo Libâneo (1989), a Tendência Liberal Renovada defende a ideia de que a educação é um processo interno e não externo; faz parte das necessidades e interesses individuais necessários para a adaptação ao meio. A educação parte da própria experiência 
humana, e a escola renovada propõe um ensino que valorize a auto-educação - o aluno como sujeito do conhecimento, a experiência direta sobre o meio pelas atividades - o ensino torna-se centrado no educando e no grupo. Nesta tendência a escola tem como finalidade adequar as necessidades individuais ao meio social, e parte do pressuposto de que todo educando possui mecanismo de adaptação progressiva, e tal adaptação se dá através de experiências que devem satisfazer os interesses do aluno e das condições que a sociedade impõe.

\section{Experimentotecas}

A experimentoteca é um método de ensino que busca aliar o conteúdo teórico com a prática, proporcionando sentido ao conteúdo que está sendo desenvolvido. Visa facilitar o entendimento do tema quando acompanhado de um modelo prático e interativo, de maneira que corresponda a um meio de troca de experiências entre aluno e professor e expresse o conteúdo teórico de forma acessível e simples.

Para Passos (2000) a materialidade para amenizar as dificuldades de ensino teve influência a partir do Movimento Escola Nova, que defendia o uso de material concreto para que os alunos pudessem aprender fazendo, ou seja, manuseando. Entretanto, grande parte dos professores teve uma compreensão restrita desse processo, ao compreender que a simples manipulação empírica destes objetos levaria à aprendizagem de conceitos complexos.

Lorenzato (2006, p. 18) define material didático como "[...] qualquer instrumento útil ao processo de ensino e aprendizagem". Esta definição inclui materiais como giz, jogos, cartaz, caderno e caneta. Em meio a essa variedade de materiais, o autor destaca o material didático concreto que, de acordo com ele, pode ter duas interpretações: "[...] uma delas refere-se ao palpável, manipulável e a outra, mais ampla, inclui também imagens gráficas" (LORENZATO, 2006, p. 22-23).

Tomazello e Schiel (1998) referem-se à experimentoteca como um laboratório das Ciências da Natureza que pretende racionalizar o uso de material experimental, da mesma maneira que uma biblioteca pública facilita o acesso de publicações a um público extenso. Compreende-se que o termo "racionalizar" posto por esses autores denota o significado de subsidiar o trabalho do professor com o uso de materiais experimentais em sala de aula. A ideia principal das experimentotecas é ser um instrumento pedagógico auxiliando o professor nas aulas de Geografia a realizar as atividades experimentais a fim de enriquecer suas aulas. 


\section{Ensino em Solos}

O tema solo foi recentemente inserido na Educação Ambiental, na década de 1990, em alguns países europeus, na Rússia, na Austrália, na Índia e no Brasil. A iniciativa de divulgação do uso racional e sustentável do solo e de sua conservação fez com que se estabelecesse, em 1998, uma comissão intitulada Soil Education and Public Awareness, na Sociedade Internacional de Ciência do Solo.

Segundo Muggler, Pinto Sobrinho e Machado (2006) em artigo publicado na Revista Brasileira de Ciência do Solo, sugere que o termo Ensino de Solos seja substituído por Educação em Solos, na Sociedade Brasileira de Ciência do Solo, pois as pessoas em geral precisam ter uma conscientização pedológica e não só receber passivamente os conceitos sobre o solo. A Educação em Solos busca conscientizar da importância do solo na vida e no cotidiano. Neste sentido, o solo deve ser visto como componente essencial do meio ambiente e da vida e, dessa forma, deve ser (re)conhecido e preservado da degradação.

Para Muggler et al. (2004) a educação em solos é um instrumento importante para promover a conscientização ambiental, expandindo a percepção, cuja importância é geralmente desconsiderada e pouco valorizada. A percepção do ambiente e seus componentes ainda é incompleta, especialmente no que se refere ao solo.

Nos Parâmetros Curriculares Nacionais (PCN's), o solo é um tema transversal, isto é, deve ser tratado em várias disciplinas curriculares, como, por exemplo, no Ensino Fundamental, em Ciências e Geografia (BRASIL, 1997). Observando os livros didáticos de Geografia e Ciências do Ensino Fundamental e livros paradidáticos, conseguimos identificar os conteúdos sobre o solo e suas deficiências. Em geral, o conceito de solo aparece em segundo plano, mal elaborado e com conceitos incorretos ou ultrapassados.

O solo é visto somente do ponto de vista econômico, não havendo nenhuma ou pouca relação com sua origem, formação, potencialidades, nova classificação, problemas e conservação. Segundo Oliveira (2005) os livros didáticos apresentam conceitos superficiais, ultrapassados e incorretos, pois a deficiência também está presente na formação dos professores e autores de livros didáticos sobre o tema solo. O solo não é valorizado nos estudos de educação ambiental, assim como o ar, a água, os seres vivos e as rochas.

\section{Morfologia do solo}

Conforme Lima (2007) a morfologia do solo significa o estudo e a descrição da sua aparência no meio ambiente natural, conforme as características visíveis a olho nu, ou perceptíveis. Com isso, os principais atributos observados na descrição morfológica são: 
cor, consistência, textura e estrutura. Todas as características morfológicas observadas em campo no perfil do solo são de fundamental importância para a caracterização do solo, com as análises químicas, físicas e mineralógicas executadas em laboratório.

Segundo Streck et al. (2002) as características morfológicas representam a aparência do solo no campo, sendo visível a olho nu ou perceptíveis ao manipular as amostras, e a sua observação no perfil é utilizada na identificação de solos, na avaliação da capacidade de uso da terra, no diagnóstico da causa de variações no crescimento de plantas e no diagnóstico de degradação em propriedades do solo.

Para Rodrigues (2018) os aspectos morfológicos aplicados à classificação do solo são determinados por meio da interpretação de características morfológicas e de propriedades físicas, químicas e mineralógicas descritas em campo e analisadas em laboratório. A descrição morfológica externa do solo, quando realizada em campo, corresponde ao ato de registrar as suas características, utilizando a observação, a avaliação e o exame da camada superficial em seu meio de ocorrência natural.

\section{Consistência do solo}

Lima (2007) entende por consistência a influência que as forças de coesão e de adesão exercem sobre os constituintes do solo, de acordo com seus variados estados de umidade. A força de coesão refere-se à atração de partículas sólidas. A força de adesão está relacionada coma atração das moléculas de água pela superfície das partículas sólidas, e são aspectos práticos da consistência, que são facilmente observados, a dureza que certos solos apresentam quando secos, ou a pegajosidade que alguns apresentam quando molhados, a consistência pode variar ao longo do perfil do solo, nos seus diferentes horizontes.

A consistência do solo é acometida pelo tipo de argilominerais, textura, matéria orgânica e umidade existente, dando a ideia de dureza no solo, quando seco, e de plasticidade e pegajosidade quando molhado, sendo também um importante indicativo do melhor estágio para a mecanização do solo (RODRIGUES, 2018). Para Santos et al. (2005) nos diferentes estados da consistência do solo verifica-se a adesão e a coesão das partículas do solo, que podem variar em função da taxa, matéria orgânica e mineralogia e devem ser observadas em campo.

- Consistência do solo seco (dureza)

Segundo Lima (2007) a expressão da consistência quando o solo está seco (dureza) é a resistência à ruptura dos torrões. Desta forma, determina-se a dureza, ao pegar um torrão 
de solo seco, a fim de tentar quebrá-lo com os dedos, ou,se não for possível, com a(s) mão(s). A consistência do solo seco varia de solta até extremamente dura.

Uma amostra de um solo extremamente duro não pode ser quebrada mesmo utilizando ambas as mãos. Através da consistência seca do solo é possível avaliar o grau de resistência à quebra ou esboroamento do torrão, podendo ser classificada em solta, macia, ligeiramente dura, dura, muito dura, e extremamente dura (SANTOS et al., 2005).

- Consistência do solo úmido (friabilidade)

É também determinada a partir de um torrão de solo, mas este deve estar ligeiramente úmido (não molhado). Tenta-se romper o torrão úmido com os dedos (ou, se necessário, com a mão), para verificar a resistência à pressão. Este estado de consistência é conhecido como friabilidade e pode variar de solta a extremamente firme (SANTOS et al., 2005). Empiricamente, os produtores rurais normalmente preferem preparar o solo neste estado de consistência, pois o solo oferece menor resistência, tendo em vista que as forças de coesão e adesão são menores (LIMA, 2007).

O aluno poderá observar que a força utilizada para romper um torrão úmido é menor que se ele estivesse seco, pois diminuem as forças de coesão entre as partículas de solo. Para Santos et al. (2005) a consistência úmida do solo é medida pela friabilidade do torrão ligeiramente úmido. É classificada em solto, muito friável, friável, firme, muito firme e extremamente firme.

- Consistência do solo molhado

É caracterizada pela plasticidade e pegajosidade, sendo determinada em amostras de solo molhadas. É observada a plasticidade quando o material do solo, no estado molhado, ao ser manipulado pode ser modelado constituindo diferentes formas (por exemplo, moldar e dobrar um fio entre 3 e 4 milímetros), ela varia de não plástica até muito plástica (SANTOS et al., 2005). A plasticidade do solo é uma propriedade muito utilizada pelos professores de artes, mas é útil ao engenheiro civil, ao artesão e ao agricultor.

Através da consistência molhada do solo é possível observar amostras molhadas, amassadas e homogeneizadas nas mãos. Avalia-se a plasticidade, ou seja, a capacidade de o material ser moldado. Classificado em três categorias, são elas: não plástica, ligeiramente plástica e muito plástica. Já a pegajosidade (capacidade de aderência) também é classificada em três categorias: não pegajosa, ligeiramente pegajosa e muito pegajosa (SANTOS et al., 2005). 
A pegajosidade refere-se à aderência do solo a outros objetos, quando molhado. Para determinar a pegajosidade, uma amostra de solo é molhada e comprimida entre o indicador e o polegar, estimando-se a sua aderência. A pegajosidade varia de não-pegajosa (não gruda nos dedos) até muito pegajosa (SANTOS et al., 2005). O solo muito pegajoso é difícil de ser trabalhado para diversas finalidades, como construção de um aterro por um engenheiro civil, ou o cultivo por um produtor rural. Um equívoco comum, oriundo do senso comum, é achar que todo solo argiloso é muito pegajoso e extremamente duro, o que nem sempre ocorre. A consistência do solo é altamente correlacionada com a textura e atividade da fração de argila, este atributo ocorre por atuação das forças de adesão e coesão entre as partículas do solo, que variam com o grau de umidade do solo (LIMA, 2007).

Para Lepsch (2002), no interior dos agregados, as partículas de areia, silte e argila aderem umas às outras, sendo assim mantidas unidas com diferentes graus de adesão, isto faz com que uns solos sejam mais macios e outros mais duros. A resistência do material do solo, em estado natural, a alguma força que tende a rompê-lo é conhecida como consistência e, na prática, é determinada pressionando-se um agregado ou torrão de determinado horizonte do solo entre os dedos. O grau de consistência do solo pode variar em função de uma série de outras características do solo, tais como textura, estrutura, agentes cimentantes (matéria orgânica, óxidos de ferro), como do teor de umidade existente nos poros por ocasião de sua determinação. Sendo assim, a consistência do solo pode ser determinada em três estados de umidade: a) molhado - para verificação da plasticidade e pegajosidade; b) úmido - para verificação de friabilidade; c) seco - para verificação de dureza ou tenacidade.

Streck et al. (2002) explicam que a consistência se refere à resistência do material do solo quanto à deformação e ruptura. Ela é condicionada pelas forças de coesão e adesão que atuam na massa do solo, conforme o conteúdo de água presente. No solo seco caracteriza-se o grau de dureza, isto é, a resistência dos agregados à ruptura ou fragmentação. No solo úmido caracteriza-se a friabilidade, ao passo que no solo molhado caracteriza-se a plasticidade e a pegajosidade. A friabilidade é a resistência dos agregados úmidos à ruptura e a sua posterior capacidade do solo molhado ser moldado. A pegajosidade é a propriedade que o solo tem de aderir a objetos, como arados ou pneus do trator. A consistência do solo tem implicações diretas no seu manejo e deve-se identificar qual a melhor condição de umidade para trabalhar o solo. A umidade excessiva do solo favorece a compactação. O estado de consistência friável é o mais indicado para o preparo do solo. 


\section{RESULTADOS/DISCUSSÕES}

A primeira metodologia aplicada foi da Tendência Liberal Tradicional, e a aula ocorreu de forma organizada na turma de controle (62), onde inicialmente foi exposto o objetivo da pesquisa para os educandos e em seguida deu-se início às atividades. A aula começou com a apresentação do tema (solos), em seguida foram abordados os aspectos morfológicos do solo. A Figura 1 ilustra o momento em que o conteúdo foi exposto e dialogado.

Figura 1 - Conteúdo de solos sendo exposto aos educandos da turma de controle (62)

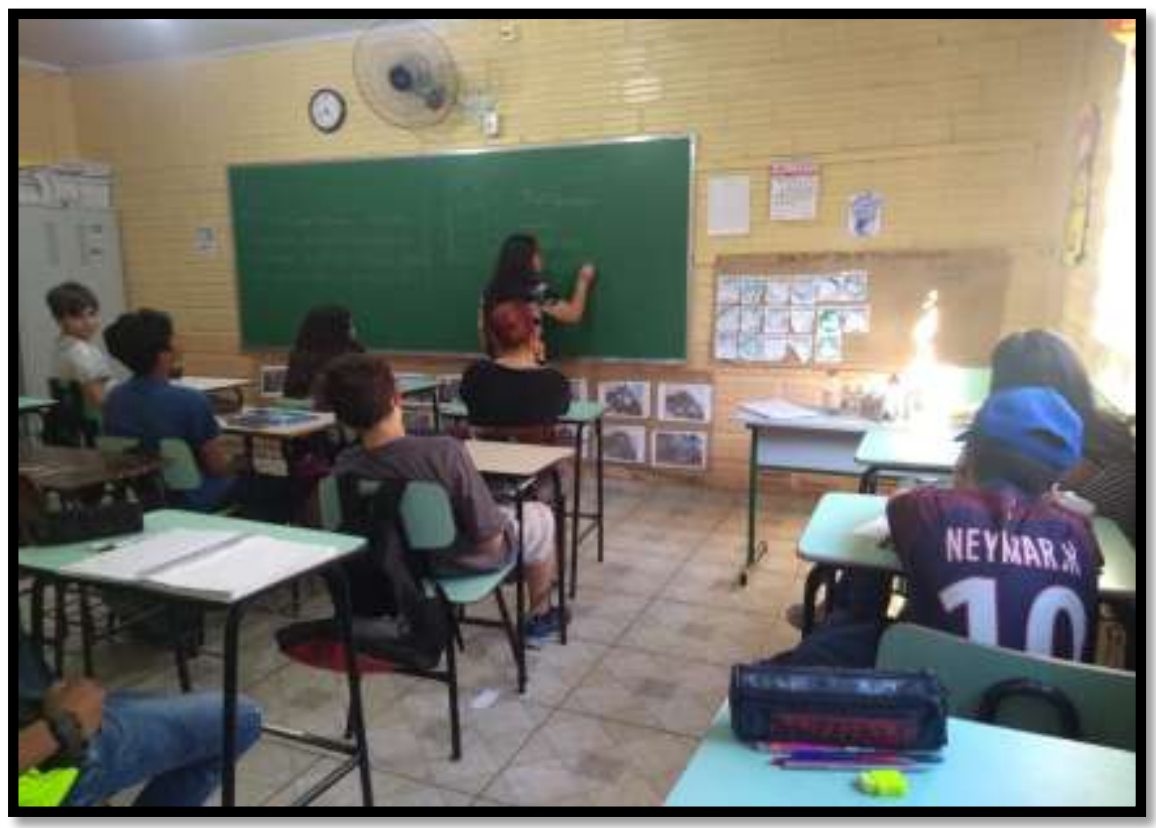

Fonte: as autoras.

A aula foi predominantemente expositiva, e como material de apoio utilizou-se apenas o livro didático Expedições Geográficas para o $6^{\circ}$ ano e o quadro negro. $O$ método de ensino utilizado foi o tradicional, a aula desenvolveu-se de forma branda, os educandos mantiveram-se em silêncio na maior parte do tempo.

$\mathrm{Na}$ turma de trabalho foi aplicado o método de ensino proposto pela Tendência Pedagógica Liberal Renovada Progressista,a qual sugere as experimentotecas como instrumento de ensino e aprendizagem. Inicialmente, os educandos foram convidados a colocar as amostras de solo nos copos Becker, cada amostra em seus respectivos copos. As amostras ficaram em três diferentes estados de consistências, e a amostra arenosa manteve-se seca. Na amostra siltosa os educandos colocaram uma pequena quantidade de água, o suficiente para deixá-la úmida. Já na amostra argilosa foi necessário colocar uma quantidade considerável de água. Em seguida os educandos agitaram a amostra com o 
bastão para poder manuseá-la e fazer a descrição dos aspectos morfológicos através das suas percepções.

Através desse experimento os educandos manusearam as amostras determinando 0 estado de umidade de cada uma delas, ou seja, a consistência do solo seco, úmido e molhado. As amostras possuíam torrões para facilitar a análise das características, tais características puderam ser observadas através da visão e do tato, ao manuseá-las, e a audição quando as levaram próximo ao ouvido e os educandos observaram os ruídos entre os grãos através da granulometria. A amostra arenosa permaneceu seca, os educandos comprovaram a dureza que ela possui, e a resistência ao pressioná-la entre os dedos, a consistência do agregado arenoso estava ligeiramente solta, quando pressionado, os educandos relataram que o solo arenoso é áspero quando seco, e semelhante a pequenas "pedrinhas". Já a amostra siltosa estava ligeiramente úmida, a qual os educandos pressionaram o torrão de solo com os dedos tentando rompê-lo para verificar a resistência à pressão e a friabilidade da amostra.

Ao avaliar o solo siltoso concluíram ser um solo levemente firme, quando comparado ao solo arenoso que facilmente desagrega-se, entretanto quando o pressionaram entre os dedos perceberam que, devido ao tamanho dos grãos e sua consistência úmida, rapidamente desagregou-se sem colocar muita força. O solo argiloso estava com a consistência molhada, o que possibilitou analisar a plasticidade e a pegajosidade da amostra; a plasticidade pode ser compreendida ao manipularem as amostras e analisar a sua capacidade de moldar, de dobrar e de fazer diferentes formatos. A Figura 2 ilustra o momento em que os educandos da turma de trabalho (61) estão manipulando e modelando as amostras, já úmidas, para verificar a plasticidade e pegajosidade.

Os educandos classificaram a argila como plástica, pois facilmente conseguiram modelá-la em fios, referidos na forma coloquial de "cobrinhas". Foram trabalhados, ainda, conceitos acerca da pegajosidade da argila quando molhada, que se refere à aderência do solo a outros objetos ou nos dedos quando está sendo manipulado; a amostra argilosa em questão apresentou pegajosidade.

Ao observar a participação e o envolvimento dos educandos na experimentoteca em solos, conclui-se que, o recurso apresentou forte aceitação pelos educandos, visto que essa prática despertou o interesse e a curiosidade por ser uma prática diferenciada das aulas tradicionais comumente realizadas. O Quadro 2 apresenta os métodos utilizados para mediar a aula conforme as tendências pedagógicas.

Ao examinar o Quadro 2 é possível constatar que ambas as tendências pedagógicas estão interligadas, cada uma possui viés diferenciado nas suas práticas, entretanto suas manifestações não são exclusivas e em alguns casos as tendências se complementam. Para desenvolver a aula experimental na turma de trabalho proposta pela Tendência Liberal 
Renovada Progressivista foi necessário abordar conceitos, relacionando-os com os princípios e conhecimentos que deram sustentação teórica acerca do ensino em solos e seus aspectos morfológicos que foram desenvolvidos durante a experimentação. Foi imprescindível usar a aula expositiva no primeiro momento, e posteriormente dialogada, para expor o conhecimento base e, dessa forma, criar a sustentação teórica.

Figura 2 - llustra os educandos da turma de trabalho desenvolvendo e praticando a experimentoteca

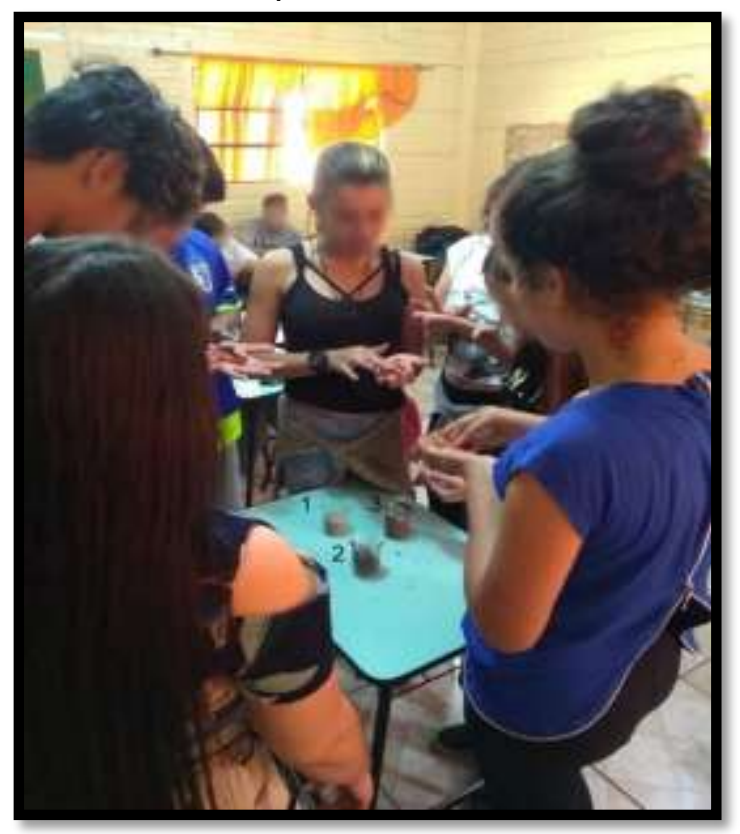

Fonte: as autoras.

Quadro 2 - Relação dos métodos entre as tendências

\begin{tabular}{|l|c|c|}
\hline Parâmetros & $\begin{array}{l}\text { Tendência Liberal } \\
\text { Tradicional }\end{array}$ & $\begin{array}{l}\text { Tendência } \\
\text { Renovada Progressivista }\end{array}$ \\
\hline Livro Didático & $\mathrm{X}$ & $\mathrm{X}$ \\
\hline Expositiva & $\mathrm{X}$ & $\mathrm{X}$ \\
\hline Dialogada & $\mathrm{X}$ & $\mathrm{X}$ \\
\hline Experimental/Pratica & & $\mathrm{X}$ \\
\hline Participativa & & \\
\hline Dinâmica em grupo & & \\
\hline
\end{tabular}

Fonte: as autoras.

A aula se tornou dialogada e prática simultaneamente, e utilizaram-se ambos os métodos, mas nenhum de forma absoluta. A prática da experimentoteca teve grande aceitação e nitidamente os educandos compreenderam melhor o conteúdo mostrando interesse em aprender e envolveram-se na atividade com expressivo entusiasmo. Indo de encontro com o pensamento de Castellar (2011) as pedagogias ativas e as metodologias participativas devem orientar o trabalho pedagógico, de forma que o aluno se sinta participante do processo de construção do conhecimento. 
As tendências são complementares, uma não anula a outra, neste caso compreendemos que a prática de experimentoteca foi sim, eficaz, e os educandos conseguiram observar na prática os conceitos, contudo foi necessária uma explicação teórica, podemos considerar que a primeira parte da aula foi na turma de trabalho se baseou em conceitos mais tradicionais, para que, na prática, pudesse ter eficácia.

Segundo Santos (1964) a Pedagogia Liberal Tradicional era viva nas escolas, especialmente no que tange às escolas religiosas que adotaram a orientação clássicohumanística ou uma orientação humano-científica. Este modelo é o mais recorrente e predominante na história educacional brasileira e vinha sendo alvo de diversas críticas, o professor tradicional de Geografia visto como vilão e um ensino insuficiente que precisa evoluir. Santos (1964) compreendia que o ensino moderno se baseava na atividade prática, visto que o educando não deve se deter apenas em ouvir a aula e anotar o que é dito pelo professor. A aula deve ser como um organismo vivo, em que o aluno participa, discute, trabalha e aprende.

\section{CONCLUSÕES}

Compreende-se que não se deve desprezar o uso do livro didático e a importância da explanação realizada pelo professor de Geografia, já que, para compreender a prática (experimentotecas), é fundamental que o professor tenha embasamento teórico acerca dos conteúdos e demais conceitos para discutir a teoria junto aos educandos. Com a aplicação das experimentotecas notou-se que a aprendizagem pode ocorrer de forma significativa em qualquer conteúdo, desde que uma nova informação se ancore em conceitos relevantes (subsunçores) preexistentes na estrutura cognitiva do educando.

As experimentotecas apresentaram excelentes resultados devido às práticas de manusear as amostras; através do sistema sensorial os educandos puderam explorar e observar os aspectos morfológicos com maior facilidade do que se tivessem apenas observando a ilustração nos livros didáticos. Dessa forma, compreendemos que ambas as tendências são eficazes, mas cada uma com sua finalidade específica.

Durante as práticas de experimentotecas entende-se que esta é de fato é uma boa ferramenta para avançar a educação em solos no contexto escolar, especialmente no que tange ao ensino da morfologia do solo. Com isso, as experimentotecas comprovaram a hipótese inicial da pesquisa, sendo um excelente instrumento de ensino e uma opção pertinente para a educação em solos no ensino fundamental. Ao observar a participação e o envolvimento dos educandos nas experimentotecas em solos, infere-se que o recurso apresentou forte aceitação pelos educandos, visto que essa prática despertou o interesse e a curiosidade por ser uma prática diferenciada das aulas habituais comumente realizadas. 
Dessa forma, o ensino em solos necessita ser ampliado e compreendido como um componente essencial; os professores de Geografia precisam sensibilizar os educandos sobre a degradação do solo e os problemas que esse processo pode desencadear. Deste modo, as práticas de experimentotecas vêm preenchendo essa lacuna com o objetivo de tornar as aulas dinâmicas e participativas; embasadas na teoria Liberal Renovada Progressivista.

Através da Teoria Renovada Progressivista buscou-se a conscientização acerca da importância da conservação do solo, indo de encontro com Muggler, Pinto Sobrinho e Machado (2006) que afirmam a necessidade da consciência pedológica, buscando a "Educação em Solos", visto que muitos professores de Geografia não conseguem compreender tal importância no contexto ambiental e para a manutenção dos ecossistemas e, consequentemente, da paisagem.

Com base na revisão bibliográfica compreende-se que na tendência tradicional, por sua vez, não há a interação professor-aluno, pois não apresenta relação com o cotidiano do educando e muito menos com as realidades sociais. Neste sentido, esta tendência necessita evoluir principalmente no que tange ao papel dos educandos e de suas experiências. Através da prática pedagógica observou-se que os resultados são satisfatórios quando os educandos participam de forma ativa, como se comprovou ao longo da aplicação do método indicado pela Tendência Renovada Progressivista.

\section{REFERÊNCIAS}

BRASIL. Ministério Da Educação e do Desporto. Secretaria de Educação Fundamental. Parâmetros Curriculares Nacionais de Geografia. Apresentação de temas transversais e ética. Brasília: MEC, 1997.

BREVIK, Eric C. The teaching of soil Science in Geology, Geography, Environmental Science, and Agricultural Programs. Soil Survey Horizons, Madison, v. 50, n. 4, p. 120123, 2009.

CASTELLAR, Sonia Maria Vanzella. Mudança na prática docente: a aprendizagem em espaços não-formais. In: REGO, Nelson; CASTROGIOVANNI, Antonio Carlos; KAERCHER, Nestor André. Geografia: práticas pedagógicas para o ensino médio. Porto Alegre: Penso, 2011. v. 2, p. 67-84.

FIELD, Damien J. et al. Soil Science teaching principles. Geoderma, Amsterdam, v. 167168, p. 9-14, Nov. 2011.

HARTEMINK, Alferd E. et al. The joy ofteaching soil Science. Geoderma, Amsterdam, v. 217-218, p. 1-9, Apr. 2014.

LAGAR, Fabiana; SANTANA, Bárbara Beatriz de; DUTRA, Rosimeire. Conhecimentos pedagógicos para concursos públicos. Brasília: Gran Cursos, 2013.

LEPSCH, Igo F. Formação e conservação dos solos. São Paulo: Oficina de Textos, 2002. 
LIBÂNEO, José Carlos. Democratização da escola pública: a pedagogia crítico-social dos conteúdos. São Paulo: Loyola, 1989.

LIMA, Marcelo Ricardo de. Noções de morfologia do Solo. In: LIMA, Valmiqui Costa; LIMA, Marcelo Ricardo de; MELO, Vander de Freitas. O Solo no meio ambiente: abordagem para professores do ensino fundamental e médio e alunos do ensino médio. Curitiba:

Universidade Federal do Paraná, 2007. p. 17-26.

LORENZATO, Sérgio. O laboratório de ensino de matemática na formação de professores. Campinas: Autores Associados, 2006.

LUCKESI, Cipriano Carlos. Filosofia da educação. São Paulo: Cortez, 1993.

MUGGLER, Cristine Carole et al. Solos e educação ambiental: experiência com alunos do ensino fundamental na zona rural de Viçosa, MG. In: CONGRESSO BRASILEIRO DE EXTENSÃO UNIVERSITÁRIA, 2., 2004, Belo Horizonte. Anais [...]. Belo Horizonte: Universidade Federal de Minas Gerais, 2004. p. 1-6.

MUGGLER, Cristine Carole; PINTO SOBRINHO, Fábio de Araújo; MACHADO, Vinícius Azevedo. Educação em solos: princípios, teoria e métodos. Revista Brasileira de Ciência do Solo, Viçosa, v. 30, n. 4, p. 733-740, 2006.

OLIVEIRA, Silmara Sartoreto de. Concepções alternativas e ensino de biologia: como utilizar estratégias diferenciadas na formação inicial de licenciados. Revista Educar, Curitiba, n. 26, p. 233-250, 2005.

SANTOS, Maurício Silva. O ensino da Geografia no curso secundário noturno. Boletim Geográfico, Rio de Janeiro, v. 22, n. 179, p. 212-216, mar./abril., 1964.

SANTOS, Raphael David dos et al. Manual de descrição e coleta de solo no campo. Viçosa: SBCS/EMBRAPA/CNPS, 2005.

STRECK, Edemar Valdir et al. Solos do Rio Grande do Sul. Porto Alegre: Universidade Federal do Rio Grande do Sul, 2002.

PASSOS, Carmen Lúcia Brancaglion. Materiais manipuláveis como recursos didáticos na formação de professores de matemática. In: LORENZATO, Sergio (org.). Laboratório de ensino de matemática na formação de professores. Campinas: Unicamp, 2000. p. 38-40.

RODRIGUES, Renato Augusto Soares. Ciência do solo: Morfologia e Gênese. Londrina: Editora e Distribuidora Educacional S. A, 2018.

TOMAZELLO, Maria Guiomar Carneiro; SCHIEL, Dietrich. O livro da experimentoteca: educação para as ciências da natureza através de práticas experimentais. Piracicaba: Gráfica Alves, 1998.

Recebido: dezembro de 2020. Aceito: junho de 2021. 